\title{
Variação discursiva e gramaticalização: o controle de condicionamentos semântico-pragmáticos e o princípio da persistência
}

\author{
Discourse variation and grammaticalization: controlling of semantic-pragmatic conditionings \\ and the principle of persistence
}

Maria Alice Tavares ${ }^{1}$

Doutorado em Linguística pela Universidade Federal de Santa Catarina. Professora associada III do Rio Grande do Norte e da Pós-Graduacão em Estudos da Linguagem da mesma instituicão. Bolsista de produtividade em pesquisa do CNPa. Este trabalho está vinculado ao Projeto Variaçäo e gramaticalizaçăo na indicaçâa da SRPI: um estudo sociofuncionalista comparativo, que recebeu apoio do Conselho Nacional de Desenvolviment 308245/2011-3). A constituicão do Banco de Dados FALA-Natal foi autorizada pelo Comitê de Etica em Pesquisa (CEP) da Universidade Federa do Rio Grande do Norte (parecer no 244.207/CAAE

Emait alcovos
RESUMO: À luz da sociolinguística variacionista e de estudos sobre a gramaticalização, considero os conectores sequenciadores e, aí e então como variantes da variável discursiva "sequenciação retroativo-propulsora de informações". Os dados são oriundos de 24 entrevistas sociolinguísticas provenientes do Banco de Dados FALA-Natal. Tenho os seguintes objetivos: (i) analisar os padrões de distribuição dos conectores sequenciadores e, aí e então quanto a um grupo de fatores de natureza semântico-pragmática; (ii) relacionar indícios diacrônicos referentes ao processo de gramaticalização sofrido por cada conector a seus padrões de distribuição sincrônica. Os resultados revelam que o grupo de fatores "relação semântico-pragmática" é bastante significativo no condicionamento da variável discursiva investigada. Com base nesses resultados, observei que o uso dos conectores sequenciadores parece ser motivado pelo princípio da persistência, uma vez que esses conectores são, em geral, favorecidos por relações semântico-pragmáticas que manifestam alguns traços em comum a suas fontes diacrônicas de gramaticalização.

PALAVRAS-CHAVE: Variação discursiva; Gramaticalização; Princípio da persistência.

ABSTRACT: Under the light of variationist sociolinguistics and studies on grammaticalization, I take the sequence connectors $e$, aí and então as variants of discursive variable "retroactive-propeller sequenciation of information". The data come from 24 sociolinguistic interviews from the FALA-Natal Data Base. I have the following objectives: (i) to analyze the patterns of distribution of sequence connectors $e$, aí and então regarding a semantic-pragmatic factor group; (ii) to relate diachronic evidence for the grammaticalization process undergone by each connector to their synchronic distribution patterns. The results show that the factor group "semantic-pragmatic relationship" is highly significant in conditioning the discursive variable examined. Based on these results, I noticed that the use of sequence connectors seems to be motivated by the principle of persistence, since the sequence connectors are, in general, favored for semantic-pragmatic relations that show some common features to their diachronic sources of grammaticalization.

KEYwoRDS: Discourse variation; Grammaticalization; Principle of persistence. 


\section{Introdução}

$\mathrm{N}$ este texto, alicerçado na sociolinguística variacionista e em estudos sobre o processo de gramaticalização, abordo um fenômeno de variação no plano da articulação do discurso. A variável linguística objeto da investigação é a sequenciação retroativo-propulsora de informações; as variantes são os conectores sequenciadores $e$, aí e então, os mais frequentes na codificação da sequenciação de informações no corpus utilizado, composto por entrevistas sociolinguísticas pertencentes ao Banco de Dados FALANatal (BDFN). Seguem algumas ocorrências:

(1) Sim, eu estava um dia jogando, aí eu fui entrar na loja de uma pessoa, aí tinha um buraco enorme $e$ eu caí $e$ perdi meus seis diamantes e minha armadura completa de ferro. Fiquei muito triste, muito mesmo. (NAT27) ${ }^{1}$

(2) Acho que se tivesse emprego não- não tinha tanto assim- Até mesmo que nem eles fazem agora, exige estudo, né? Então o pessoal estuda pra manter o emprego, né? Aí eu acho que mudaria, né? muita coisa. (NAT34)

Cada um dos conectores destacados nos exemplos acima indica que o enunciado prévio se relaciona com o enunciado subsequente e instiga o ouvinte a procurar por possíveis relações semântico-pragmáticas existentes entre os enunciados assim interligados (cf. maior detalhamento adiante).

Embora relativamente recentes, as pesquisas que se voltam a fenômenos variáveis discursivos já têm apresentado importantes contribuições teóricometodológicas no que tange à descrição e análise desse tipo de fenômeno. Uma dessas contribuições foi a incorporação de propostas advindas de estudos sobre gramaticalização à investigação da variação discursiva,

${ }^{1}$ O código que segue o trecho da entrevista a identifica. Por exemplo, $($ NAT27) $=$ informante de natal (NAT), entrevista número 27 considerando que tais propostas permitem a elaboração de explicações mais refinadas para os padrões sincrônicos de distribuição de variantes discursivas cuja origem histórica reside em processos de gramaticalização. Essa interface variação-gramaticalização pode ser frutífera inclusive para explicar condicionamentos semânticos e pragmáticos ao uso das variantes, como veremos a seguir.

Neste estudo, tenho como objetivos: (i) analisar os padrões de distribuição dos conectores sequenciadores $e$, aí e então quanto a um grupo de fatores de natureza semântico-pragmática; (ii) relacionar indícios diacrônicos referentes ao processo de gramaticalização sofrido por cada conector a seus padrões de distribuição sincrônica.

Na seção 1, sintetizo pressupostos teórico-metodológicos fundamentais para este estudo. Em continuação, seção 2, descrevo e exemplifico a sequenciação retroativo-propulsora de informações, elenco os procedimentos metodológicos adotados e analiso os resultados obtidos. Por fim, apresento as considerações finais.

\section{Variação discursiva e gramaticalização}

Pesquisas feitas sob a égide da sociolinguística variacionista trouxeram evidências de que a língua é uma estrutura heterogênea, isto é, inerentemente variável, sincrônica e diacronicamente. Essas pesquisas dedicam-se a investigar fenômenos de variação e mudança linguística envolvendo formas alternativas de mesmo significado ou função - ditas 'formas variantes' -, que são vistas como competindo entre si, sob o condicionamento de fatores linguísticos, sociais e estilísticos pertinentes a seu contexto de uso. Um conjunto de formas variantes recebe o rótulo de "variável linguística" e constitui o objeto de estudo da sociolinguística variacionista. 
As escolhas que um falante faz entre variantes de uma determinada variável linguística não são aleatórias; uma vez submetidas à quantificação, revelam padrões regulares de distribuição no que se refere a fatores contextuais que a impactam, ou seja, a heterogeneidade linguística é ordenada (cf. WEINREICH; LABOV; HERZOG, 2006 [1968]). Além de ser uma característica essencial da língua, a variação é também um prérequisito para a mudança linguística, podendo representar uma etapa de um processo de mudança em andamento que pode eventualmente resultar em mudança categórica em um período de tempo posterior (cf. LABOV, 2008 [1972]).

A variação linguística pode acontecer em qualquer nível da língua, do fonético-fonológico ao discursivo. Neste texto, trato de uma variável discursiva, a sequenciação retroativo-propulsora de informações, cujas variantes, os conectores $e$, aí e então, atuam na articulação entre porções do discurso.

As formas gramaticais que desempenham papéis de natureza discursiva são, de acordo com Pichler (2010, p. 596), "recurso indispensável para os interlocutores na construção e na interpretação do discurso, bem como para o estabelecimento e a manutenção da interação social."2 Variáveis discursivas, à semelhança de variáveis de qualquer nível gramatical, manifestam heterogeneidade ordenada e podem sofrer mudança. Os padrões de variação de alternantes discursivas são condicionados por fatores diversos, linguísticos e extralinguísticos, destacando-se aqueles de ordem semântica e pragmática. Pichler (2010, p. 583-584) afirma que a "operação de restrições semânticas e pragmáticas sobre traços discursivos afeta a frequência crucial para a análise quantitativa", podendo "superar o efeito de fatores sociais sobre a variabilidade discursiva".

${ }^{2}$ As traduções são de minha responsabilidade.
Fatores semânticos e pragmáticos condicionadores da variação discursiva são frequentemente correlacionados ao processo de gramaticalização (cf. CHESHIRE, 2007; GÖRSKI et al., 2003; ITO; TAGLIAMONTE, 2003; LEVEY; GROULX; ROY, 2014; PICHLER; LEVEY; 2011; POPLACK, 2011; TAVARES, 2003, 2014, entre outros), que pode fundamentar explicações não apenas para a origem da variação, mas também para padrões de distribuição sincrônica das variantes.

Pichler (2013, p. 40), apoiando-se em estudiosos que "advogam uma noção abrangente de gramática que engloba significados pragmáticos $\mathrm{e}$ reconhece o status dos traços discursivo-pragmáticos como elementos legítimos e integrais da gramática", propõe uma "explicação da evolução diacrônica e das propriedades sincrônicas de traços discursivo-pragmáticos em termos da gramaticalização." Adoto aqui essa proposta.

Através da gramaticalização, "itens e construções lexicais passam, em certos contextos linguísticos, a servir a funções gramaticais e, uma vez gramaticalizados, continuam a desenvolver novas funções gramaticais" (HOPPER; TRAUGOTT, 2003, p. xv). A gramaticalização é considerada uma das principais fontes da variação morfossintática e discursiva porque, graças a ela, podem emergir, ao longo do tempo, novas formas para a representação de uma função gramatical, formas essas que passam a coexistir e, não raro, a competir com as formas mais antigas (cf. TORRES CACOULLOS, 2011, p. 148). Ou seja, "em muitos casos, a variação sincrônica é um sintoma de mudanças longitudinais que foram acontecendo durante um longo tempo" (TAGLIAMONTE, 2012, p. 207), podendo as variantes "ter diferentes fontes lexicais bem como diferentes histórias na língua” (TAGLIAMONTE; D’ARCY, 2009, p. 3).

Nessa perspectiva, o exame do background histórico das formas variantes é fundamental para contextualizar - e explicar - a variação sincrônica. Os padrões de variação podem revelar traços das fontes lexicais 
e/ou de diferentes etapas do processo de gramaticalização percorrido por cada variante que ainda estejam sendo preservados em seu uso variável, o que costuma ser relacionado, na literatura da área, a um dos princípios de gramaticalização propostos por Hopper (1991), o princípio da persistência (cf. D'ARCY et al., 2013; TAGLIAMONTE, 2012; TAVARES, 2014; TORRES CACOULLOS, 2011).

Segundo esse princípio, matizes dos significados originais de um item linguístico tendem a aderir a ele, conservando-se ao longo do processo de gramaticalização. Isso pode fazer com que detalhes da história desse item sejam refletidos na forma de condicionamentos morfossintáticos e semântico-pragmáticos a seu uso variável, mesmo quando o item assume significados gramaticais distanciados daqueles dos quais provém. Sendo assim, é possível que os conectores sequenciadores e, aí e então, objeto deste estudo, difiram quanto a seus padrões de distribuição sincrônica porque se desenvolveram de fontes distintas e preservaram traços delas, questão a ser retomada a seguir.

\section{Relações semântico-pragmáticas e percursos de gramaticalização}

A sequenciação retroativo-propulsora de informações é uma função gramatical responsável pela introdução de informações ${ }^{3}$ no discurso através do estabelecimento de uma relação coesiva de continuidade e consonância entre enunciados, de modo que o primeiro serve de base para o que será dito no segundo. É o que o rótulo "sequenciação retroativo-propulsora" busca

\footnotetext{
3 Por "informação" compreendo o que é dito/escrito, sejam fatos/eventos ou argumentos/ideias. Todas essas unidades seguem uma organização linear no discurso: fatos/eventos podem ser ordenados temporalmente de acordo com o momento em que ocorrem no mundo real; argumentos/ideias podem se preceder ou seguir logicamente (cf. SCHIFFRIN, 1987).
}

sintetizar: os movimentos simultâneos de retroagir - guiando a atenção para trás no discurso - e de propulsionar - guiando a atenção para a frente, para a continuidade do discurso (cf. TAVARES, 2003, 2014). ${ }^{4}$

$E$, aí e então são os conectores mais frequentemente utilizados, no corpus utilizado neste estudo, como indícios linguísticos para que o ouvinte perceba a relação de sequenciação retroativo-propulsora entre informações estabelecida pelo falante. Esses conectores podem ser tomados como variantes, uma vez que são formas funcionalmente equivalentes que ocorrem em contextos análogos (cf. TAVARES, 2015).

As formas gramaticais que desempenham papéis de natureza discursiva são, de acordo com Pichler (2010, p. 596), "recurso indispensável para os interlocutores na construção e na interpretação do discurso, bem como no estabelecimento e na manutenção da interação social". Os conectores sequenciadores $e$, aí e então atuam no plano da "construção" e "interpretação do discurso": indicam que o enunciado prévio se relaciona com o enunciado subsequente e instigam o ouvinte a procurar por possíveis relações semântico-pragmáticas existentes entre os enunciados assim interligados.

Delimitei quatro relações semântico-pragmáticas ligadas aos contextos de ocorrência da sequenciação retroativo-propulsora de informações nas entrevistas sociolinguísticas do Banco de Dados FALA-Natal: sequenciação textual, sequenciação temporal, consequência e retomada. Essas relações podem ser percebidas a partir de indícios on-line vários: o que foi dito antes, o que se seguiu, inferências e implicaturas em jogo no momento da interação. O movimento retroativo-propulsor característico se faz presente a cada caso.

${ }^{4}$ Para um maior detalhamento dos critérios que embasam a decisão teórico-metodológica de tomar a sequenciação retroativo-propulsora de informações como variável linguística, conferir Tavares $(2012$ 2014). 
A opção que fiz de distinguir entre si essas quatro relações semânticopragmáticas foi pautada na observação de seu grau de rotinização: elas são notadas com regularidade na fala de Natal. Também corrobora com a validade da distinção entre as relações semântico-pragmáticas em questão o fato de que nuanças idênticas também são apontadas em outros estudos - vários pesquisadores as observaram em amostras de fala de diferentes regiões brasileiras, o que indica que são salientes no discurso (cf. ANDRADE, 1997; FREITAG et al., 2013; MARTELOTTA, 1994; RISSO, 1996; SANTOS, 2003; SILVA; MACEDO, 1992; SOUZA, 2010).

Abaixo, as quatro relações semântico-pragmáticas são descritas e exemplificadas:

(i) Sequenciação textual: assinala a ordem sequencial pela qual as informações são apresentadas e desenvolvidas no discurso, indicando a progressão destas para a frente sem a emergência de matizes mais específicos de significado.

(3) Então quando eu f- disse isso na minha mente, minha língua começou a suavizar e eu comecei a abrir. (os olhos) ${ }^{5}$ Quando eu abri, não vi mais ninguém. Então eu acho que são experiências espirituais que a gente tem na vida, né? e que Deus dá quando a gente tá merecendo. Naquele dia eu tenho certeza que eu tava merecendo ver meu irmão. (NAT25)

(4) Aqui eu torço pelo $\mathrm{ABC}$, né? Coitado! Vai jogar amanhã, se ele perder amanhã, tá fora. $E$ no sul eu torço pelo Santos. É porque eu morei em Santos, e no- no tempo que eu morei em Santos, Pelé jogava no segundo quadro do Santos. (NAT42)

(ii) Sequenciação temporal: sequencializa temporalmente eventos, introduzindo-os na ordem de ocorrência no tempo.

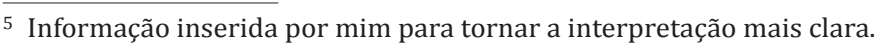

(5) Aí faço o peito de frango, cozinho o peito de frango, desfio o peito de frango, deixo ele de lado. Aí vou pro macarrão, deixo o macarrão cinco minutinhos no fogo cozinhando, tiro, aí começo a montar a lasanha. (NAT33)

(6) Na hora que eu acordo, eu acordo $e$ escovo os dentes, tomo café, tomo banho. (NAT47)

(iii) Consequência: introduz informações que representam consequência em relação ao que foi dito anteriormente.

(7) Sim, eu estava um dia jogando, aí eu fui entrar na loja de uma pessoa, aí tinha um buraco enorme e eu caí $e$ perdi meus seis diamantes e minha armadura completa de ferro. Fiquei muito triste, muito mesmo. (NAT27)

(8) Mas a escola não, a escola é diferente, porque tem o dia marcado pra aquilo acontecer. Então você é criança, não tem outro compromisso pra ir, é uma coisa diferente pra fazer, então você vai. [E]- e é assim, é aquele momento, né? (NAT35)

(iv) Retomada: recupera o assunto interrompido por digressões.

(9) Eu num gostei um dia, sabe? não tem aqueles helicópteros, né? da polícia? Ele tava procurando ladrão, aí eu peguei, né? tava lá na- na minha calçada, \{ que é muito perigoso, né? ficar assim em calçada. \} Aí eu peguei e fiquei lá, né? (NAT46) ${ }^{6}$

(10) E eu, na bobeira, eu tava com uma pochete, uma bolsa aqui, né? tirei o dinheiro pra conferir se dava pra pagar aquela conta, í porque eu semprejá assim pra não [ter]- passar vexame na hora assim de você chegar no caixa e não ter o dinheiro, ý então tirei e comecei a conferir: "Ah não, dá. Tem o troco assim, assim. Tem que dar de troco, então vamos ver se o troco vai dar, pra conferir." (NAT31)

Provenientes de fontes distintas, $e$, aí e então tornaram-se conectores sequenciadores através de processos de gramaticalização. $\mathrm{O} e$ chegou à

6 O símbolo í, acrescentado ao dado, marca o início da digressão feita pelo falante, e ý marca o seu final 
língua portuguesa já com a função de conector, oriundo do et latino. A fonte do processo de gramaticalização do et como conector é conhecida: trata-se do advérbio et, proveniente do advérbio eti, 'além de', do protoindo-europeu. No latim arcaico, et, como advérbio, substituiu etiam 'também'. Posteriormente, passou a ser utilizado para indicar uma cópula, isto é, uma junção entre construções linguísticas, tornando-se um conector (cf. ERNOUT; MEILLET, 1951 apud BARRETO, 1999; cf. tb. SILVEIRA BUENO, 1965, CUNHA, 1991; RAMAT; MAURI, 2011).

Realizei um estudo diacrônico em busca de indícios dos percursos de gramaticalização seguidos por e, aí e então valendo-me de 40 textos escritos em língua portuguesa do século XIII ao XX (TAVARES, 2003). Esse estudo revelou que, nos primórdios da língua portuguesa (séculos XIII e XIV), o $e$ já indicava sequenciação textual, sequenciação temporal e consequência, como ilustram as seguintes ocorrências:

(11) Germaydade ou aiûtamêto de dous moesteyros ou de duas eygreias podê fazer. $E$ esto pode ser em tres maneyras: a primeyra he quando hûu moesteyro metê so poderio doutro ca entõ aquela que he sometuda da outra deue viuer so a rregla daquela so que a metê a vsar dos costumes e dos priuilegios sseus daquela so que é sometud[a]. (Alphonse X - Primeyra Partida, p. 412)

(12) E depoys resucitouse en carne e amostrouse aos seus dicipulos $\underline{\boldsymbol{e}}$ comeu com elles e leyxous confirmados em ss fe sancta catholica $e$ subyo aos ceos en corpo en dignidade $e$ ende uerra na cruz eneste mundo dar juyzo aos boos e aos maos. (Foro Real, p. 127)

(13) E Asdrubal que entom tiinha o senhorio da Spanha, quãdo soube que Magon, seu irmãao, fora vençudo e preso, foi muy quebrantado em seu coraçom $e$ trabalhou quanto pode de ajuntar gram poder (...). (Crônica Geral de Espanha de 1344, p. 93)
Em (11), temos um trecho de Alphonse X - Primeyra Partida, obra do século XIV. Há aí um caso em que o $e$ sequencia textualmente, de acordo com a cronologia discursiva, informações relevantes para o mesmo tópico, qual seja a congregação de dois mosteiros ou duas igrejas. Em (12), em um trecho do Foro Real, obra do século XIII, aparecem algumas ocorrências em que o $e$ sequencia eventos consoante sua ordem de ocorrência no tempo. Por fim, em (13), em um trecho da Crônica Geral de Espanha de 1344, o e é utilizado para denotar a relação semânticopragmática de consequência: Asdrúbal se sentiu mortificado ao saber que seu irmão fora preso e, por essa razão, buscou aliar forças para combater os inimigos.

O $e$ é utilizado como marca linguística dessas três relações semânticopragmáticas do português arcaico em diante. No entanto, a primeira relação que deve ter sido indicada pelo $e$ é a sequenciação textual, pois essa é a relação que apresenta os traços mais similares aos de seus antigos empregos como advérbio vinculado à soma entre informações, empregos em que significava 'além de', 'também', significados esses que evidenciavam, à semelhança da sequenciação textual, a característica de adicionar uma porção do discurso à outra

O aí e o então derivam de fontes anafóricas espaciais e temporais latinas (cf. SILVEIRA BUENO, 1965; CUNHA, 1991). Eles possivelmente tornaram-se conectores sequenciadores através da relação de sequenciação temporal, visto que essa é a relação que manifesta nuanças mais semelhantes àquela de seus usos no plano anafórico temporal. Quando o aí e o então adquiriram o papel de conectores, a relação temporal que os ligava anaforicamente a um elemento antecedente no discurso deu vez à relação de sequencialidade temporal entre dois eventos (cf. MARTELOTTA, 1994; TAVARES, 2014). 
O então é utilizado, na língua portuguesa, na indicação das relações de sequenciação textual, sequenciação temporal e consequência desde os séculos XIII e XIV. ${ }^{7}$ Observemos algumas ocorrências:

(14) Asdrubal era homem de gram coraçom e nõ quedou de trabalhar da sua parte. E êvyou a Africa por gram companha e outrossy polos Spanhooes que com elle tiinham ê Espanha e juntou muy grãde hoste e foy cõtra os Romaãos e soubeo fazer per tal guysa que elles nõ forom percebudos delle se nõ tarde. Entõ os Romaãos nõ estavã todos juntos cõ os Cepiõoes, ca erã spargidos pella terra que avyã gaanhada. (Crónica Geral de Espanha de 1344, p. 90)

(15) E diz o outor que se o cedro que Deus nõ chantou for talhado seerá de gram proveyto per que entêdemos o pecador que nõ fazia nê hûû bõõ fruyto no mûdo. Quando Deus brita e talha per algûa coyta, soffre depois muy bê o carrego da peendêça na Eigreja de Deus. E esto se faz quando Deus brita o cedro, o sobervhoso, pelo seu poderio. Este Deus brita este cedro, o pecador, vingando-sse Del. Entonce o queyma no fogo perduravil do inferno. In Domino confido quomodo dicitis anime mee transmigra î mote sicut passer. (Livro das Aves, p. 41)

(16) E, despois que foi enno alcacer, êfraqueceulhe o corpo, ca lhe desfalleçiam ja os espiritus vidaaes. E esto era quando erã ainda por ãdar VII dias do prazo. Entõ mãdou ãte si trajer as boçetas do ouro que lhe mãndara o soldõ, en que estava a mirra e o balsamo, e mãdou que lhe trouxessem hûua copa d'ouro per que soia de bever; e tomou daquelle balsamo e mirra quanto hûa pequena colhar e miscrou todo cõ rossada e beveua. (Crónica Geral de Espanha de 1344, p. 176-177)

Quanto ao aí, acredito que seu uso como conector tenha surgido bem mais recentemente, pois, em 40 textos datados do século XIII ao XX, obtive

\footnotetext{
Além da forma então, também encontrei, nos textos escritos em português do século XIII ao século XX, as variações formais entõ enton e entonce
}

dados desse conector apenas em português brasileiro ${ }^{8}$ a partir da primeira metade do século XX, já codificando as relações de sequenciação textual, sequenciação temporal e consequência (cf. TAVARES, 2003), como nas ocorrências que seguem:

(17) - Eu não preciso de cachaça - interpôs-se o motorista com rapidez. - Eu 'tou é treinando o cérebro o tempo todo. - Ficou segurando o volante só com a direita e falou animado: - Supunha que eu passo por uma estrada. Aí passa também um sujeito qualquer. Eu fico olhando pra êle e depois que passa por mim procuro lembrar tudo sobre ele; como era a roupa que êle usava, os sapatos, o chapéu e como êle andava e até a altura dêle, o pêso, alguma marca, cicatriz, etc. Já consigo fazer isso muito bem. Formo um retrato do homem, direitinho, na minha cabeça. (STEINBECK, 1940, p. 16)

(18) Bem, agora o senhor pode ajudar. Preste atenção: eu vou bater, que é pra afrouxar um pouco êsse troço. Aí o senhor tira êsses parafusos em cima e eu tiro os parafusos de baixo. Cuidado com o mancal. (STEINBECK, 1940, p. 181)

(19) Melhor mesmo era ficar ao lado de tia Margarida e se conter. Dava a impressão de que nada tinha acontecido ontem. Restaria um vazio dentro dela, tia Margarida ficaria confusa, não ia poder nunca saber com certeza se aquilo tinha mesmo acontecido. Era tão fácil, Deus podia ajudar que tia Margarida ficasse confusa. Aí ela jamais ia poder saber se tinha sonhado, se apenas imaginou, se alguma coisa realmente aconteceu. Um momento de fraqueza, uma alucinação de tia Margarida. Tão sozinha na vida, coitada! (AUTRAN DOURADO, 1970, p. 170-171)

Quanto à relação semântico-pragmática de retomada, trata-se de um tipo de emprego específico da relação de sequenciação textual e, portanto,

${ }^{8}$ Em outro estudo, comparando conectores sequenciadores na fala do português brasileiro e do português europeu, não localizei nenhuma ocorrência do aí como conector no português europeu, o que é forte indício de que esse uso se desenvolveu apenas no português brasileiro (cf. TAVARES, o que 2 . 
derivado desta. A retomada é uma estratégia discursiva que serve para destacar a volta à linha narrativa ou argumentativa interrompida por uma digressão. Essa relação semântico-pragmática é bastante genérica em termos de matizes de significado, exibindo, a exemplo da sequenciação textual, apenas sucessão discursiva.

No entanto, seu papel no plano da articulação textual é bastante complexo: reintroduz informações previamente mencionadas, fornecendo pistas para o interlocutor acerca da volta da sequência discursiva que vinha sendo desenvolvida e que fora interrompida por uma digressão. Geralmente, no processo de retomada, a informação reatada com o trecho discursivo subsequente reaparece de forma literal ou com a alteração de alguns vocábulos, como se verifica nas ocorrências (7) e (8) anteriormente apresentadas.

Embora e aí e então devam ter sido utilizados inicialmente na indicação de uma relação semântico-pragmática específica, aquela que contava com mais traços de significados semelhantes aos de suas fontes adverbiais, com o tempo todos esses conectores passaram a ser utilizados variavelmente na indicação das quatro relações semântico-pragmáticas aqui consideradas. ${ }^{9}$

Na próxima seção, descrevo os procedimentos metodológicos adotados, teço as hipóteses relativas à distribuição dos conectores $e$, aí e então no que tange às relações semântico pragmáticas, e analiso os resultados obtidos à luz do princípio da persistência.

\section{Relações semântico-pragmáticas: indícios de persistência}

Analisei 1.047 dados produzidos em 24 entrevistas sociolinguísticas feitas com informantes de Natal (RN), estratificados homogeneamente em

\footnotetext{
${ }^{9}$ Conferir em Tavares $(2003$,2014) mais informações sobre as etapas dos percursos de gramaticalização possivelmente seguidos pelos conec evolução. 0 percurso de gramaticalização de cada conector não é aqui detalhado por questão de espaço.
}

relação ao sexo (feminino, masculino), à idade (25 a 49 anos, mais de 50 anos), è escolaridade (ensino fundamental 1, ensino fundamental 2, ensino médio).

Essas entrevistas integram o Banco de Dados FALA-Natal (BDFN), ${ }^{10}$ atualmente em fase final de constituição. O estado do Rio Grande do Norte ainda não contava com um banco de dados de fala representativo para a realização de estudos sociolinguísticos. Propus-me a iniciar a organização desse banco de dados, a ser denominado Banco de Dados da Fala do Rio Grande do Norte (FALA-RN), pela coleta do corpus de Natal (o Banco de Dados FALA-Natal), através de entrevistas com membros da comunidade de fala desse município, que é a capital e maior centro urbano do estado (cf. TAVARES, 2016). Posteriormente, serão organizados corpora referentes a comunidades de fala do interior.

Uma vez que os conectores sequenciadores $e$, aí e então são bastante recorrentes nas entrevistas sociolinguísticas que serviram de fonte para este estudo, considerei apenas os 30 minutos finais das entrevistas, que têm cada uma cerca de 60 minutos de duração. Como grupos de fatores condicionadores, além da relação semântico-pragmática, controlei também a sequência textual, o nível de articulação, o grau de conexão, o sexo, o nível de escolaridade e a idade do informante (cf. TAVARES, 2015). ${ }^{11}$

Submeti os dados a tratamento quantitativo multivariado através do programa estatístico GOLDVARB X (cf. SANKOFF; TAGLIAMONTE;

${ }^{10} \mathrm{~A}$ constituição do Banco de Dados FALA-Natal foi autorizada pelo Comitê de Ética em Pesquisa (CEP) da Universidade Federal do Rio Grande do Norte (parecer no 244.207/CAAE 11652312.2.0000.5537) Foram controladas cinco sequências textuais (narrativa, procedimentos, descrição de vida, descrição argumentação) e quatro níveis de articulação (entre orações, entre segmentos tópicos, entre subtópicos argumentação) e quatro niveis de articulação (entre oraçoes, entre segmentos tópicos, entre subtópicos e entre tópicos). O grau de conexão foi controlado através de um valor numérico atribuído conforme havia alteração de elementos entre a oração introduzida pelo conector e a oração precedente (po exemplo, alteração quanto a sujeito, tempo, aspecto, modo, presença de elementos interferentes etc.) de conexão (equivalente ao valor 5)) 
SMITH, 2005), para cálculo de frequências, percentuais e pesos relativos, ${ }^{12}$ e para a identificação da ordem de significância dos grupos de fatores. Realizei rodadas binárias do programa, considerando cada variante versus as demais. Na sequência, apresento os resultados referentes à relação semântico-pragmática.

Como a variação discursiva tende a receber forte influência de fatores de ordem semântico-pragmática (cf. PICHLER, 2010, 2013), decidi controlar as relações semântico-pragmáticas vinculadas aos contextos de ocorrência da sequenciação retroativo-propulsora como um grupo de fatores passível de condicionar o uso dos conectores e, aí e então.

Como visto na seção anterior, esses conectores podem ser utilizados variavelmente na sinalização de cada uma das quatro relações semânticopragmáticas focalizadas, mas tenho por hipótese de que cada conector tem seu aparecimento favorecido na sinalização da relação semânticopragmática para a qual inicialmente migrou em seu processo de gramaticalização.

Portanto, o $e$ deve ser favorecido em contextos de sequenciação textual, e o aí e o então devem ser favorecidos em contextos de sequenciação temporal. Para tecer essa hipótese, levo em conta o princípio da persistência descrito na seção anterior, segundo o qual "padrões de distribuição antigos podem persistir, mesmo nos estágios mais avançados de gramaticalização" (POPLACK, 2011, p. 223).

${ }^{12} \mathrm{O}$ peso relativo é uma medida multidimensional ou multivariada importante para a pesquisa variacionista, pois resulta do controle simultâneo de vários elementos contextuais (no formato de múltiplas variáveis independentes/grupos de fatores) capazes de influenciar a variável linguística. Em uma análise multivariada, “(...) cada efeito de um fator na análise é calculado enquanto são controlados, até o máximo possível, os outros fatores" (GUY; ZILLES, 2007, p. 100). Os pesos relativos variam de 0 a 1. Quanto mais próximo de 0 for o peso, menos influente é o fator que o recebeu; quanto mais próximo 1. Quanto mais proximo de 0 for o peso, menos influente é o fator que o recebeu; quanto mais próximo de 1, maior é a influência. Um peso de valor 0.50 tende a ser indiferente, mas, "embora isso geralmente seja verdadeiro, não é o modo mais preciso de se conceber os pesos dos fatores. A posição relativa (TAGLIAMONTE, 2006, p. 145).
Na Tabela 1 a seguir constam os resultados obtidos pelo controle da influência das relações semântico-pragmáticas sobre o uso dos conectores sequenciadores $e$, aí e então em Natal.

Tabela 1 - Influência das relações semântico-pragmáticas sobre o uso de E, AÍ e ENTÃO - Natal

\begin{tabular}{|c|c|c|c|c|c|c|c|c|c|}
\hline \multirow{2}{*}{ Relações } & \multicolumn{3}{|c|}{$\mathbf{E}$} & \multicolumn{3}{|c|}{ AÍ } & \multicolumn{3}{|c|}{ ENTÃO } \\
\hline & Ap./Total & $\%$ & PR & Ap./Total & $\%$ & PR & Ap./Total & $\%$ & PR \\
\hline Seq. Textual & $263 / 478$ & 55 & 0.68 & $152 / 478$ & 32 & 0.33 & $63 / 478$ & 13 & 0.50 \\
\hline Seq. Temporal & $147 / 313$ & 47 & 0.40 & $157 / 313$ & 50 & 0.73 & $09 / 313$ & 03 & 0.20 \\
\hline Consequência & $33 / 136$ & 24 & 0.20 & $58 / 136$ & 43 & 0.60 & $45 / 136$ & 33 & 0.78 \\
\hline Retomada & $28 / 120$ & 23 & 0.34 & $42 / 120$ & 35 & 0.38 & $50 / 120$ & 42 & 0.82 \\
\hline \multirow[t]{2}{*}{ Total } & $471 / 1.047$ & 45 & & $409 / 1.047$ & 39 & & $167 / 1.047$ & 16 & \\
\hline & \multicolumn{3}{|c|}{ 2o selecionado } & \multicolumn{3}{|c|}{$1^{o}$ selecionado } & \multicolumn{3}{|c|}{ 1o selecionado } \\
\hline
\end{tabular}

A hipótese de que o conector $e$ seria favorecido pela relação de sequenciação textual foi atestada, com frequência de $55 \%$ e peso relativo de 0.68. Também foi atestada a hipótese de que o conector aí seria favorecido pela relação de sequenciação temporal, com frequência de $50 \%$ e peso relativo de 0.73 . O conector aí também foi favorecido pela relação de consequência, com frequência de $25 \%$ e peso relativo de 0.60 . No que se refere ao conector então, a hipótese de que seria favorecido pela sequenciação temporal não se confirmou, sendo esse conector favorecido por outras duas relações, consequência, com frequência de $33 \%$ e peso relativo de 0.78 , e retomada, com frequência de $42 \%$ e peso relativo de 0.82 .

Portanto, em consonância com a previsão inicial, o conector $e$ teve sua utilização positivamente condicionada na indicação da relação semânticopragmática que mais manifesta traços de suas fontes latinas, cuja propriedade essencial é a soma entre informações. 
Por sua vez, o conector aí é positivamente condicionado na indicação das relações de sequenciação temporal e consequência. É possível que o componente temporal dessas duas relações esteja subjacente a tal condicionamento: ambas apresentam traços de temporalidade mais fortes se comparadas às outras duas relações, evidenciando-se a sequenciação cronológica de eventos em todos os dados de sequenciação temporal e em parte dos dados de consequência, aqueles que apresentam traços de sucessão cronológica mesclados aos de consequência.

Outros estudiosos, como Abreu (1992), Silva e Macedo (1996) e Freitag et al. (2013), também constataram a existência de uma forte correlação quantitativa entre o conector aí e a sequenciação temporal de eventos. A indicação da passagem de tempo pode estar tão fortemente vinculada à opção pelo conector aí devido a seus usos fontes no âmbito da anáfora temporal. Assim, a tendência à preservação de resquícios de usos passados também parece se manifestar no caso desse conector.

Uma surpresa é a restrição à utilização do conector então na sinalização da sequenciação temporal, com frequência de $3 \%$ e peso relativo de 0.20 . Essa relação semântico-pragmática possivelmente serviu como porta de entrada para os usos do então como conector, uma vez que apresenta um traço semântico-pragmático em comum com alguns de seus usos fontes no plano anafórico: a indicação temporal.

Talvez o então tenha passado ou esteja ainda passando por um processo de distanciamento da sinalização de traços temporais oriundos de suas fontes anafóricas temporais, o que estaria refletido nos resultados acima descritos. Esse processo pode ter se iniciado há bastante tempo, visto que, em um estudo anterior, contando com dados de textos escritos nos séculos XIV, XVI e XVIII, observei haver um maior emprego do então na indicação de sequenciação temporal no século XIV em relação a seu emprego na indicação de consequência, o que se inverte nos séculos XVI e XVIII, com um uso maior do então na indicação de consequência (cf. TAVARES, 2000).

O então, nas entrevistas sociolinguísticas que servem de fonte para este estudo, também é favorecido pela consequência, e desfavorecido pela sequenciação temporal. Com o passar do tempo, é possível, portanto, que o então tenha sido cada vez menos vinculado à esta relação semânticopragmática e mais àquela. Além disso, esse conector tem sido bastante utilizado na indicação de outra relação, a retomada, como revelam os resultados obtidos neste estudo.

Cabem ainda algumas palavras sobre a importância do grupo de fatores relações semântico-pragmáticas no condicionamento do uso dos conectores $e$, aí e então: esse grupo de fatores foi selecionado, pelo programa estatístico GOLDVARB X, na seguinte ordem de significância: em segundo lugar para o $e$, e em primeiro lugar para o aí e o então.

Como previamente mencionado, Pichler $(2010,2013)$ alerta para o fato de que, em casos de variação discursiva, fatores de natureza semânticopragmática podem ser de grande relevância, superando inclusive fatores de natureza social. No caso deste estudo, no que se refere aos grupos de fatores sociais controlados, sexo, idade e nível de escolaridade, o $e$ teve o sexo, a idade e a escolaridade selecionados em terceiro, quarto e quinto lugar, respectivamente; o aí teve a idade selecionada em quarto e o escolaridade em quinto lugar; e o então teve a escolaridade selecionada em segundo e o sexo em terceiro lugar. Ou seja, o grupo de fatores relações semântico-pragmáticas superou, para cada conector, em ordem de significância estatística, todos os grupos de fatores sociais controlados.

\section{Considerações finais}

Neste texto, apresentei a análise de uma variável discursiva, a função gramatical de sequenciação retroativo-propulsora de informações, cujas 
variantes mais frequentes, no corpus considerado, são os conectores e, aí e então. Esses três conectores são empregados na sinalização de quatro relações semântico-pragmáticas vinculadas ao contexto de ocorrência da sequenciação retroativo-propulsora de informações: sequenciação textual, sequenciação temporal, consequência e retomada. No entanto, cada conector manifesta tendências distintas no que se refere à distribuição quanto a essas relações semântico-pragmáticas: o $e$ é favorecido pela sequenciação textual, o aí pela sequenciação temporal e pela consequência, e o então pela consequência e pela retomada.

Os fatores que condicionam a escolha do $e$ e do aí parecem consistentes com as trajetórias de desenvolvimento gramatical possivelmente percorridas por eles ao longo do tempo, alinhando-se ao previsto pelo princípio da persistência, que reza que matizes dos significados de usos fontes podem persistir em usos gramaticais derivados por gramaticalização, influenciando sua distribuição sincrônica. Em contraste, o então foi fortemente desfavorecido na indicação sequenciação temporal, a relação semânticopragmática que mais manifesta matizes semelhantes aos de suas fontes anafóricas temporais.

Finalizo ressaltando a importância de considerarmos, na análise sincrônica de fenômenos variáveis discursivos, propostas advindas de estudos voltados à gramaticalização. Abordando a gramaticalização de uma perspectiva diacrônica, esses estudos levantam hipóteses a respeito de percursos de mudança seguidos por itens linguísticos particulares ao longo do tempo, hipóteses essas que podem ser testadas por meio da organização de grupos de fatores condicionadores.

Nessa linha de investigação, destacam-se os grupos de fatores de natureza semântico-pragmática, imprescindíveis para a investigação de variáveis discursivas. Tais grupos de fatores, operacionalizados com base em fontes e etapas dos processos de gramaticalização sofridos pelas formas que compõem o conjunto de variantes estudadas, contribuem para que sejam fornecidas explicações mais completas, fundamentadas diacronicamente, para as tendências sincrônicas de distribuição semântico-pragmática das variantes.

\section{Referências}

ABREU, Maria Teresa V. Elementos conjuntivos: sua variação em narrativas orais e escritas 1992. Dissertação (Mestrado em Linguística) - Universidade Federal do Rio de Janeiro, Rio de Janeiro, 1992.

Alphonse X - Primeyra Partida. Edição e estudo de José de Azevedo Ferreira. Braga, Instituto Nacional de Investigação Científica. 1980. p. 120-123, 144, 409-414. (Obra do século XIV).

ANDRADE, Maria Lúcia C. V. O. Digressão: uma estratégia na condução do jogo textualinterativo. In: $\mathrm{KOCH}$, Ingedore V.; BARROS, Kasue S. M. (Org.). Tópicos em linguística de texto e análise da conversação. Natal: EDUFRN, 1997. p. 180-184.

AUTRAN DOURADO, Valdomiro Freitas. O risco do bordado. 3. ed. Rio de Janeiro: Expressão e Cultura, 1974. (1. ed.: 1970).

BARRETO, Therezinha M. M. Gramaticalização das conjunções na história do português. 1999. Tese (Doutorado em Linguística) - Universidade Federal da Bahia, Salvador, 1999.

CHESHIRE, Jenny. Discourse variation, grammaticalisation and stuff like that. Journal of Sociolinguistics, v. 11, n. 2, p. 155-193, 2007. https://doi.org/10.1111/ j.14679841.2007.00317.x

Crónica Geral de Espanha de 1344. Edição crítica de Luís Filipe Lindley Cintra. Lisboa: Imprensa Nacional/Casa da Moeda, 1990. (Obra do século XIV).

CUNHA, Antônio G. Dicionário etimológico Nova Fronteira da língua portuguesa. 2. ed. Rio de Janeiro: Nova Fronteira, 1991.

D'ARCY, Alexandra; HADDICAN, Bill; RICHARDS, Hazel; TAGLIAMONTE, Sali; TAYLOR, Ann. Asymmetrical trajectories: the past and present of -body/-one. Language Variation and Change, v. 25, p. 287-310, 2013. https://doi.org/10.1017/S0954394513000148

FREITAG, Raquel Meister K. et al. Gramática, interação e ensino de língua materna: procedimentos discursivos na fala de Itabaiana/SE. Interfaces Científicas (Educação), v. 1, n. 3, p. 71-84, 2013. 
Foro Real de Afonso X. Edição e estudo linguístico de José de Azevedo Ferreira. Lisboa: Instituto Nacional de Investigação Científica, 1987. (Tradução do foro espanhol feita nos fins do século XIII ou início do século XIV).

GÖRSKI, Edair; GIBBON, Adriana de Oliveira; VALLE, Carla Regina M.; DAL MAGO, Diane; TAVARES, Maria Alice. Fenômenos discursivos: resultados de análises variacionistas como indícios de gramaticalização. In: RONCARATI, Claúdia; ABRAÇADO, Jussara (Org.). Português brasileiro: contato linguístico, heterogeneidade e história. Rio de Janeiro: 7Letras, 2003. p. 106-122.

GUY, Gregory Riordan; ZILLES, Ana Maria Stahl. Sociolinguística quantitativa: instrumental de análise. São Paulo: Parábola, 2007.

HOPPER, Paul J. On some principles of grammaticization. In: TRAUGOTT, Elizabeth C.; HEINE, Bernd (Ed.). Approaches to grammaticalization. Amsterdam: John Benjamins, 1991. Vol. 1. p. 17-35.

_HOPPER, Paul J.; TRAUGOTT, Elizabeth C. Grammaticalization. 2. ed. Cambridge: Cambridge University Press, 2003.

ITO, Rika; TAGLIAMONTE, Sali. Well weird, right dodgy, very strange, really cool: layering and recycling in English intensifiers. Language in Society, v. 32, p. 257-279, 2003.

LABOV, William. Padrões sociolinguísticos. São Paulo: Parábola, 2008 [1972].

LEVEY, Stephen; GROULX, Karine; ROY, Joseph. A variationist perspective on discoursepragmatic change in a contact setting. Language Variation and Change, v. 25, p. 225-251, 2013. https://doi.org/10.1017/S0954394513000100

Livro das Aves. Edição crítica de Jacira Andrade Mota, Rosa Virgínia Mattos e Silva, Vera Lúcia Sampaio e N. Rossi. Rio de Janeiro: Instituto Nacional do Livro/MEC, 1965. (Obra do século XIV).

MARTELOTTA, Mário E. T. Os circunstanciadores temporais e sua ordenação: uma visão funcional. 1994. 238 fls. Tese (Doutorado em Linguística) - Universidade Federal do Rio de Janeiro, Rio de Janeiro, 1994.

PICHLER, Heike. Methods in discourse variation analysis: reflections on the way forward. Journal of Sociolinguistics, v. 14, n. 5, p. 581-608, 2010. https://doi.org/10.1111/j.14679841.2010.00455.x 2013.

The structure of discourse-pragmatic variation. Amsterdam: John Benjamins,
PICHLER, Heike; LEVEY, Stephen. In search of grammaticalization in synchronic dialect data: general extenders in northeast England. English Language and Linguistics, v. 15, n. 3, p. 441-471, 2011. https://doi.org/10.1017/S1360674311000128

POPLACK, S. Grammaticalization and linguistic variation. In: NARROG, Heiko; HEINE, Bernd (Ed.). The Oxford handbook of grammaticalization. Oxford: Oxford University Press, 2011. p. 209-224. https://doi.org/10.1093/oxfordhb/9780199586783.013.0017

RAMAT, Anna Giacalone; MAURI, Caterina. The grammaticalization of coordinating interclausal connectives. In: NARROG, Heiko; HEINE, Bernd (Ed.). The Oxford handbook of grammaticalization. Oxford: Blackwell, 2011. p. 656-667.

RISSO, Mercedes Sanfelice. O articulador discursivo "então.” In: CASTILHO, Ataliba T.; BASÍLIO, Margarida (Org.). Gramática do português falado. Campinas: UNICAMP/FAPESP, 1996. Vol. IV. p. 423-451.

SANKOFF, David; TAGLIAMONTE, Sali A.; SMITH, Eric. Goldvarb X: a multivariate analysis application. Toronto: Department of Linguistics; Ottawa: Department of Mathematics. 2005.

SANTOS, Leonor W. Articulação textual na literatura infantil e juvenil. Rio de Janeiro: Lucerna, 2003.

SCHIFFRIN, Deborah. Discourse markers. Cambridge: Cambridge University Press 1987.

SILVA, Giselle M. de Oliveira; MACEDO, Alzira V. T. Análise sociolinguística de alguns marcadores conversacionais. In: MACEDO, Alzira V. T.; RONCARATI, Claúdia; MOLLICA, Maria Cecília (Org.). Variação e Discurso. Rio de Janeiro: Tempo Brasileiro, 1996. p. 11-49.

$$
\text { . Os marcadores conversacionais em português. Rio de Janeiro, UFRJ, } 1992 .
$$
Impresso.

SILVEIRA BUENO, Francisco. Grande dicionário etimológico-prosódico da língua portuguesa. São Paulo: Saraiva, 1965.

SOUZA, Laralis N. E, AÍ e ENTÃO: uma questão de complexidade. In: Anais da XVIII Semana de Humanidades, UFRN, Natal, 2010.

STEINBECK, John. As Vinhas da Ira. Tradução brasileira por Ernesto Vinhaes e Herbert Caro. Porto Alegre: Livraria do Globo, 1940.

TAGLIAMONTE, Sali A. Analysing sociolinguistic variation. Cambridge: Cambridge University Press, 2006. 
Variationist sociolinguistics: change, observation, interpretation. Cambridge: Wiley-Blackwell, 2012.

TAGLIAMONTE, Sali A.; D'ARCY, Alexandra. Peaks beyond phonology: adolescence, incrementation, and language change. Language, v. 85, n. 1, p. 58-107, 2009. https://doi. org/10.1353/lan.0.0084

TAVARES, Maria Alice. Um percurso de abstração gradual: então nos séculos XIV, XVI, XVIII e XX. Afrikasien Brasilien Portugal. Zeit schrift zur portugiesisch sprachigen Welt, v. 2 p. $81-92,2000$.

Condicionamentos linguísticos e sociais sobre a sequenciação de informações no português oral d'aquém e d'além mar: mudança em progresso? SIGNUN: Estudos da Linguagem, v. 6, n. 2, p. 219-251, 2002.

A gramaticalização de E, AÍ, DAÍ e ENTÃO: estratificação/variação e mudança no domínio funcional da sequenciação retroativo-propulsora de informações - um estudo sociofuncionalista. 2003. 411 fls. Tese (Doutorado) - Universidade Federal de Santa Catarina, Florianópolis, 2003.

Gramática emergente: recorte de uma construção gramatical. In: SOUZA, E. R. F. (Org.). Funcionalismo linguístico: análise e descrição. São Paulo: Contexto, 2012a. p. 33-51.

$E$ em cartas escritas por Câmara Cascudo: primeiras considerações versando o conector E. In: MARTINS, Marco Antonio; TAVARES, Maria Alice (Org.). História do português brasileiro no Rio Grande do Norte: análise linguística e textual da correspondência de Luis da Câmara Cascudo a Mário de Andrade - 1924-1944. Natal: EDUFRN, 2012. p. 265-292.

A gramaticalização de E, AÍ, DAÍ e ENTÃO: variação e mudança em uma perspectiva sociofuncionalista. Natal: EDUFRN, 2014.

Variação e gramaticalização na indicação da SRPI: um estudo sociofuncionalista comparativo. Relatório de pesquisa. Impresso. 2015.

Banco de Dados FALA-Natal (BDFN). Departamento de Letras, UFRN, 2016. Banco de dados aprovado pelo Comitê de Ética em Pesquisa da UFRN. CAAE: 11652312.2.0000.5537.

TORRES CACOULLOS, Rena. Variation and grammaticalization. In: DÍAZ-CAMPOS, M. (Ed.). The handbook of Hispanic sociolinguistics. Oxford: Wiley-Blackwell, 2011. p. 148-167.
WEINREICH, Uriel; LABOV, William; HERZOG, Marvin. Fundamentos empíricos para uma teoria da mudança linguística. São Paulo: Parábola, 2006 [1968].

Recebido em 28/08/2016 Aceito em 29/01/2017. 